\title{
An Approach to Knowledge Management Support in E-Business Processes
}

\author{
Ingrid Slembek \\ Faculty of Information Technology, University of Technology, Sydney (UTS) and the CRC for \\ Enterprise Distributed Systems Technology, Australia
}

\begin{abstract}
Knowledge is increasingly being identified as the key resource of the enterprise [4]. One approach to managing this key resource is to focus on the support of organisational knowledge creation in business processes. We propose the use of a framework for business process management as the vehicle to deliver this support. Employing the theory of organisational knowledge creation developed by Nonaka [9], we identify the presence of enabling conditions required to promote knowledge creation by making comparisons with a target established for the process. Tailored knowledge management services are proposed to strengthen these enabling conditions, and we show how the framework can assist the process in their integration. Our approach is particularly suitable for delivering support to e-business processes implemented with information technology. An illustration is provided using threat identification, a knowledge intensive activity of the risk management process.
\end{abstract}

\section{INTRODUCTION}

The strong increase in global business competition since the early 90's [8] and advances in information technology have accounted for the rapid spread of ebusiness practices in many industries. These practices [7, 14] have resulted in a shift towards a higher degree of complexity in business processes, permitting vendors to be linked with their geographically distributed customers and suppliers to form a single virtual organisation [1].

Within the set of e-business processes we can identify those that are knowledge intensive, in which existing individual and organisational knowledge is used to create new knowledge for the competitive benefit of the organisation. In such processes, organisational knowledge is created through the dynamics of the 
interaction of people working together to solve problems [9]. We call them knowledge intensive business processes, simply referring to them in this paper as processes for short.

Our goal is to support processes with an emphasis on organisational knowledge creation, in line with the increasing emphasis on knowledge as a vital organisational resource [6]. We accomplish this by applying a framework, based on Continuous Process Improvement (CPI) techniques, developed for business process management in our earlier research [12]. CPI, an approach that stems from the area of Business Process Management (BPM), is continuous and iterative in nature [5] and thus suitable for use with dynamic, emerging processes. The framework has been designed with the aim of making process stakeholders aware of and facilitating the treatment of weaknesses detected in the processes. This proactive approach to support provides feedback on current process performance as compared with an organisational target. It is designed to be applied in an iterative manner, periodically cycling through the steps of data collection, analysis, evaluation, and the provision of feedback and remediation assistance to the process under examination. The architecture of the BPM framework has been designed to obtain process data seamlessly from the application software used to support the process, making it well-suited to use with e-business processes.

In this paper we refine the BPM framework to provide specific knowledge management support in processes, using Nonaka's widely-referenced $[3,5,6]$ theory of organisational knowledge creation [9] as the basis for these refinements. We illustrate its application with a knowledge intensive e-business process from the area of risk management, with a focus on identifying knowledge management services to support organisational knowledge creation in the process. This focus emphasises the importance of knowledge as an organisational resource and its contribution to the successful outcome of the process.

The next section of this paper briefly introduces the essential elements of Nonaka's spiral of knowledge creation and the BPM framework. In section 3, we demonstrate the framework's capability to identify knowledge management services to address weaknesses in the process under study. This paper finishes with a summary that includes a discussion on future research directions.

\section{ORGANISATIONAL KNOWLEDGE CREATION AND THE BPM FRAMEWORK}

We briefly describe Nonaka's theory [9] of the dynamics of organisational knowledge creation, and how it has been functionally translated in our BPM framework [12], in order to provide the reader with the background required to follow the illustration of the framework's operation in the next section. 
Nonaka's theory is based on his study of Japanese companies involved in product innovation. Knowledge comes in two basic forms, tacit, or experiential, knowledge and explicit, or codified, knowledge. An important concept of the theory is that by cycling through the four modes of knowledge conversion (tacit to tacit, tacit to explicit, explicit to explicit and explicit to tacit) in a spiral manner, knowledge is created. Through the shared experiences and interaction between individuals engaged in this spiral of knowledge creation, it is possible to create organisational knowledge that would otherwise not have been arrived at by individuals working on their own.

The model of organisational knowledge creation contains five phases: the sharing of tacit knowledge between team members; creating concepts based on successive rounds of tacit knowledge sharing; the justification or testing of created concepts; the building of a model or prototype based on the justified concepts; and cross-levelling - the distribution of new knowledge throughout the organisation [10]. These five phases repeat as many times as are necessary until concepts are refined and crystallised into a new product or service.

There are five enabling conditions which Nonaka identifies as essential to the successful promotion of the knowledge spiral: intention, autonomy, creative chaos, redundancy and requisite variety [10]. Intention indicates that the organisational goals for the process are clearly known to participants. Autonomy indicates that the process team has the independence to organise itself and take decisions. Creative chaos means that the team is faced with challenges in the process which they must work together to address. Redundancy is a condition that applies to the intentional overlapping of information available to the process team, providing it with more than the minimum required to perform its work. The final enabling condition, requisite variety, ensures that team members have information available to them in various forms through quick and flexible channels [10]. These enabling conditions are present in varying degrees in each phase of organisational knowledge creation.

The BPM framework was designed to provide three major functions, which have been tailored here to detect and address weaknesses in the enabling conditions. The first function, the business process object (Interface), is responsible for communications with the process, collecting data from and providing feedback to it. The second function provides business process data analysis (Analyser), taking the raw data collected from the process by the Interface and analysing it to identify the five organisational knowledge creation phases and the five enabling conditions which have been characterised for the process in each phase. The last function, the business process assessor (Assessor), evaluates the enabling conditions for each organisational knowledge creation phase against a pre-defined target, making recommendations for the adjustment of knowledge management services in the process to address any weaknesses detected. The Interface may facilitate their addition or removal if requested by the process, concluding a cycle of the BPM 
framework's operation. A more detailed explanation of the generic operation of the framework is presented in [12].

\section{KNOWLEDGE MANAGEMENT SERVICES FOR AN E-BUSINESS PROCESS}

In this section, the risk management process is described at a high level, followed by a walk through of the framework's application to an activity within the process. Emphasis is placed on the assessment of enabling conditions and the need for knowledge management services in a process to support organisational knowledge creation.

Risk management, as defined in the Australian and New Zealand standard, AS/NZS 4360 [13], consists of a series of activities which assist in identifying, prioritising and helping stakeholders actively make decisions about the risks they face. This standard defines the classic sequential activities involved in risk management as: establishment of context; identification of threats; assessment of risk; and treatment of risk. Monitoring and review occurs in parallel with the other activities, and if an issue is identified, a new cycle of the process is initiated from that point in the sequence of activities. The risk management process was chosen for this illustration because it is highly knowledge intensive and relies on the strong presence of enabling conditions for a successful outcome.

For our illustration, we have selected an organisation that has decided to consolidate and relocate its data centre resources in a new building, hence triggering a full cycle of the risk management process. We focus on the threat identification activity because it displays typical characteristics of an organisational knowledge creation process, including a multifunctional team of people who engage in data gathering, sorting and analysis [9].

\subsection{Analysis of the Organisational Knowledge Creation Phases}

Figure 1 shows a model of the activity for our threat identification example. The rich picture notation employed in the model is borrowed from the soft systems methodology developed by Checkland and Scholes [2]. The many roles participating in the threat identification activity are shown on the left, linked through the cloud-shaped activity to the artefacts that they use or create in the course of fulfilling their duties. Many of the team members are located at different sites, and rely on email, file servers and other information technology to support their collaboration. The artefacts shown here are all used as input information in identifying threats, with the exception of the threat ID list, which is created by the 
process. Some roles are filled by more than one person, such as with the Business Operations Area Stakeholder, which is taken by one or more participant(s) from each area, resulting in a relatively large team.

We now demonstrate how the BPM framework identifies weaknesses in the threat identification activity's knowledge resourcing. Process data is collected by the Interface as specified by the Analyser. The Analyser goes on to distinguish the threat identification activity in terms of the phases of organisational knowledge creation.

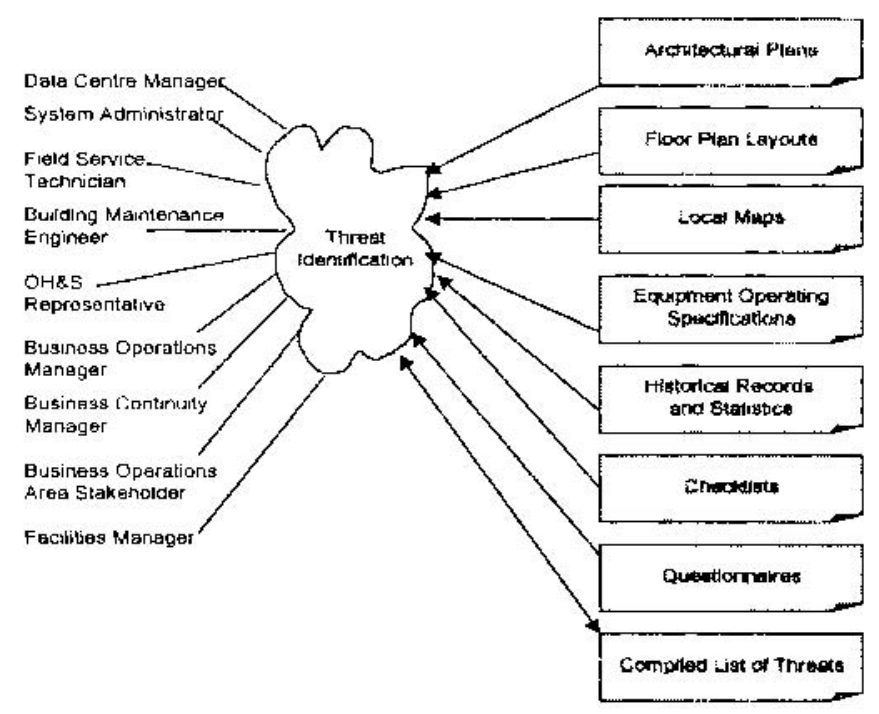

Figure 1. Rich picture of the threat identification activity

In phase 1, sharing of tacit knowledge, the organisation puts together a multifunctional team whose members represent particular business stakeholders with an interest in the continuous operation of the enterprise's data centre. An objective of this team is to assess the risk to business service continuity of the data centre's computing resources. Team members visit the new data centre location, touring its building and the surrounding streets. An opportunity for sharing tacit knowledge between team members occurs on this visit. Once an understanding of the scope and nature of the threat identification exercise is gained by the team members, phase 2 , concept creation, is entered. Each team member contributes possible threats to business service continuity by drawing on their experience and on information at their disposal. This information may take the form of architectural plans, floor plan layouts and area maps; equipment operating specifications; historical records and insurance statistics; expert opinion, such as might be expressed in community of 
practice discussion forums or newsgroups; and any other information which might prove relevant based on the nature of the threatened business service(s). The identification of threats may be facilitated through the use of checklists, questionnaires or other tools. Preliminary lists of threats are drawn up and refined in small group meetings held by threat type, including natural and man-made disasters and organisational threats. During phase 3, concept justification, with the initial list of threats compiled, the business continuity manager meets with team members representing different business operations areas to flush out further threats that may have been overlooked. Techniques employed may include scenario, fault tree, systems or other similar analysis; brainstorming and other techniques to systematically identify further threats in the areas exposed in the previous phase. The business continuity manager presents a list of identified threats to the represented business areas in order to gain agreement on and cover off any remaining threats before an overall rollup occurs at the organisational level in phase 4, building of an archetype. The business continuity manager compiles the threats by business operations area and distributes the list to the entire team. A workshop involving all team members is held, during which the representatives from each business operations area present the identified threats to the team for discussion and feedback. Following the workshop and the resolution of any resulting action items, a comprehensive list of threats is issued to the team by the business continuity manager for consideration in the next stage of risk management. In phase 5, crosslevelling of knowledge, lists of identified threats compiled during the threat identification activity are archived with other records about the risk management process. These lists reflect the organisational knowledge gained during the current activity and may provide useful input knowledge during a future iteration of the activity.

\subsection{Assessment of Enabling Conditions}

Once the Analyser has completed identification of the organisational knowledge creation phases in the process, the Assessor compares the actual enabling conditions detected against a target previously established for the process. A comparison of these is shown in Table 1, in which the letter T represents the target and the letter A the actual. Enabling conditions are listed in the leftmost column and the organisational knowledge creation phases appear in the header row.

Table 4. Assessment of the threat identification activity's enabling conditions

\begin{tabular}{lccccc}
\hline & Phase 1 & Phase 2 & Phase 3 & Phase 4 & Phase 5 \\
\hline Intention & T, A & T, A & T, A & T, A & T, A \\
Autonomy & T, A & T, A & T, A & T, A & T, A \\
Creative Chaos & - & T, A & - & - & - \\
Redundancy & T, A & T, A (weak) & T, A & T, A & - \\
Requisite Variety & T, A & T, A (weak) & T, A & - & -
\end{tabular}


Intention is clearly present at the process level through the use of the AS/NZS standard and through quality procedures in use in the organisation. This condition is expected and present in all of the organisational knowledge creation phases. Autonomy is evident through the presence of the self-organising team, whose members represent a broad range of functional areas in the organisation. This condition is expected and present in all of the organisational knowledge creation phases. Creative chaos does not factor significantly in the threat identification activity, except in phase 2, when the initial lists of threats are being compiled. In the example, the desired chaos is supplied by the challenge posed by relocation of the data centre. The nature of threat identification relies on a rich redundancy of experience and information, which is reflected in the target. Some of the team members have previously worked in departments currently represented by other members, and have held similar positions in the past. Redundancy of information should be strongly present in threat identification. Available information is drawn from the business operation and functional areas represented, but few overlapping sources were detected. This yields a weak match with the target. The final enabling condition, requisite variety, is important in threat identification since a sufficiently comprehensive list of threats will be produced only by looking at the problem from many different angles. Access to a wider variety of information sources would provide more sources for potential threats. The actual state of this enabling condition yields a weak match with the target.

\subsection{Identification of Knowledge Management Services}

After evaluation of the actual status of the enabling conditions against the target established for the process, specialised knowledge management services are recommended for inclusion in the process in a bid to bolster support for the organisational knowledge creation phases. We look at the services that are proposed to address the weaknesses identified in the information redundancy and requisite variety enabling conditions.

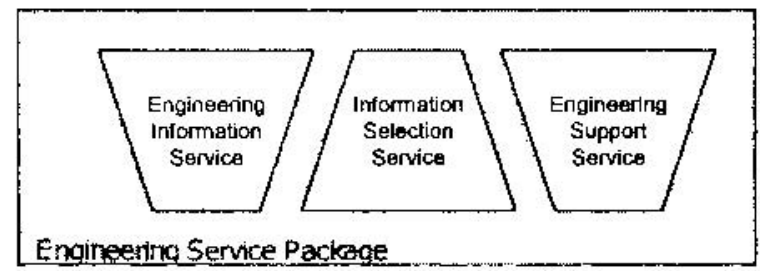

Figure 2. Knowledge management service package

As determined in the previous section, there is insufficient overlap, as well as lack of variety, in the information available to team members to aid in threat 
identification. Knowledge management services are identified through consultation with the process stakeholder and packaged by the Assessor to address these shortcomings. These services may be pre-existing in a service library or may need to be custom built. The information sources currently used by the team are evaluated and other sources applicable to the task are identified for inclusion in an information service. To support the project team members representing the building and maintenance department, an engineering information service for building-related matters supplies access to maps, drawings, architectural plans, product information and specifications for the construction materials used in the building; manufacturer and independent product fault reports; general civil engineering publications; reports by insurance bodies; and so on. For additional sources and variety of information, a support service is added that provides access to external professional discussions sponsored by civil engineering professional associations and online hotline support facilities from a consortium of international reinsurance companies. Included with the support service are internal discussion forums to which all employees in the building and maintenance department can contribute to aid in problem solving. An information selection service provides intelligent search tools for quickly locating relevant information in the support and information services. It includes filters that improve the usability of the statistical data often used with risk management by presenting it in various, including graphical, formats. Similar packages of information and support services are proposed to support the other functional areas represented by the project team.

When the threat identification activity has been completed, the search service can be used to extract important issues from the discussions for archival purposes. Thus, when modifications are made to the data centre infrastructure and the threat identification activity is revisited, a history of previous issues and decisions are available to assist the project team in putting the changes into context.

\subsection{Provision of Feedback to the Process}

With assessment complete, the Assessor provides its evaluation to the Interface, which formats and communicates it to the process. If the evaluation contains recommendations for the addition of knowledge management services, as is the case in our example, the process can elect to engage the Interface to assist with their implementation. The degree to which automated support is provided will depend on the level of integration between the BPM framework and the application software underlying the process. In the case of the engineering service package, the Interface might be asked to install one or more of the recommended services in the process and establish access to them for the building maintenance engineer and facilities manager on the project team, as well as for all employees in the building and maintenance department. Authorised process stakeholders can manually add or remove the knowledge management services as required. 
The CPI nature of the BPM framework facilitates a review of the process on a regular basis, either automatically initiated by the Interface or manually by an authorised process stakeholder. Each time a review is performed, the results of the evaluation are recorded and made available to process stakeholders. Upon completion of the process, the process log is preserved in the organisational memory along with other process data of organisational interest. Records of the knowledge management services used for a specific risk management process can be used as a basis for recommending services for subsequent instances of the same process.

\section{CONCLUSIONS AND FUTURE DIRECTIONS}

In this paper, we have approached the problem of providing support for ebusiness processes by offering knowledge management services to strengthen their organisational knowledge creation conditions. This was accomplished through the application of a CPI-based framework for business process management. The framework was adapted to identify the phases of Nonaka's spiral of organisational knowledge creation [10], and then to evaluate the presence of its enabling conditions against an established target for the process. Knowledge management services were selected to address identified deficiencies in the enabling conditions, and selectively integrated into the sample process. We demonstrated the operation of the framework's assessment function with an activity from the risk management process.

We recognise that additional work needs to be done to further develop our approach to the support of organisational knowledge creation in processes. The analysis of organisational knowledge creation enabling patterns in processes is required to develop targets for use during assessment. Matching criteria need to be established to aid in the automatic selection of knowledge management services to support identified areas of weakness in enabling conditions. The sourcing of services is also an issue. Each organisation can build its own library of services, but a more effective approach may be to seamlessly source services from vendors connected via the Internet and to negotiate for their use.

Future directions for our research include the characterisation of knowledge intensive processes in terms of knowledge management services, the refinement of an assessment approach for the identification of enabling conditions within organisational knowledge creation phases, and a business component design of the BPM framework to provide knowledge management services. We plan to interview participants in various knowledge intensive processes to define knowledge management services that are characteristic of these processes, and test our findings through the construction of a prototype. Progress made towards the definition of processes in terms of knowledge management services will help to refine the requirements for successful e-business collaboration. Designing the business process 
management framework as a set of business components will deliver the flexibility and rapid response to changing business needs required to keep e-business processes competitive [11]. It also provides a structure within which knowledge management services can be easily added and adapted to meet business needs.

Acknowledgements: The work reported in this paper has been funded in part by the Co-operative Research Centre Programme through the Australian Government's Department of the Industry, Science and Resources.

The author would like to thank Luke Cole, Valérie Gay, Dennis Hagarty, Christopher Lueg and the reviewers for their comments on drafts of this paper.

\section{REFERENCES}

1. Bultje, R. and van Wijk, J. Taxonomy of Virtual Organisations, Based on Definitions, Characteristics and Typology. VoNet: The Newsletter@http://www.virtualorganization.net, 2 (3). 7-20.

2. Checkland, P. and Scholes, J. Soft Systems Methodology in Action. Wiley, Chichester, West Sussex, England, 1990.

3. Davenport, T.H. and Prusak, L. Working Knowledge: How Organizations Manage What They Know. Harvard Business School Press, Boston, Mass, 1998.

4. Drucker, P.F. Post-Capitalist Society. HarperBusiness, New York, NY, 1993.

5. Hammer, M. and Champy, J. Reengineering the Corporation: A Manifesto for Business Revolution. Allen \& Unwin, St Leonards, NSW, 1996.

6. Johannessen, J.-A., Olaisen, J. and Olsen, B. Mismanagement of tacit knowledge: the importance of tacit knowledge, the danger of information technology, and what to do about it. International Journal of Information Management, 21. 3-20.

7. Kalakota, R. and Robinson, M. E-Business : Roadmap for Success. Addison-Wesley, Reading, Mass, 1999.

8. Kock, N. Benefits for Virtual Organizations from Distributed Groups. Communications of the ACM, 43(11). 107-112.

9. Nonaka, I. A dynamic theory of organizational knowledge creation. Organization Science, 5(1). 14-37.

10. Nonaka, I. and Takeuchi, H. The Knowledge-Creating Company: How Japanese Companies Create the Dynamics of Innovation. Oxford University Press, New York, 1995.

11. Riggins, F.J. and Rhee, H.-K., Developing the Learning Network Using Extranets. in Proceedings of the Thirty-First Hawaiian Conference on Systems Sciences, (Hawaii, 1998).

12. Slembek, I. and Gay, V., An Architecture for the Support of Knowledge-Intensive eBusiness Processes. in Proceedings of the 6th International Conference on Object Oriented Information Systems, (London, 2000), Springer Verlag, 113-120.

13. Standards_Australia AS/NZS 4360: Risk Management. Standards Association of Australia, Strathfield, NSW, 1999.

14. Yang, J. and Papazoglou, M.P. Interoperation Support for Electronic Business.

Communications of the ACM, 43 (6). 39-47. 